\title{
Dermatofibrosarcoma protuberans in a 10 -year-old child
}

\section{Uwe Wollina}

Department of Dermatology and Allergology, Academic Teaching Hospital Dresden-Friedrichstadt, Dresden, Germany.

Corresponding author:

Prof. Dr. Uwe Wollina

Department of Dematology and Allergology, Academic Teaching Hospital Dresden-Friedrichstadt

Freidrichstrasse 41

01067 Dresden, Germany

E-mail:wollina-uw@khdf.de

Key words:

dermatofibrosarcoma protuberans, child, surgery, tumor

\section{Abstract}

Background: Dermatofibrosarcoma protuberans is a rare mesenchymal malignancy in childhood and adolescence. The tumor is characterized by dermal spindle cell proliferation with infiltration of subcutaneous tissue, expression of CD34, and a specific fusion of the platelet-derived growth factor beta with the collagen type 1alpha1 gene.

Main observation: We observed a 10-year-old girl with a medaillon-like, asymptomatic plaque on the chest that was diagnosed as DSFP. The tumor was completely removed by delayed Mohs surgery. Follow-up so far has shown a complete response.

Conclusion: The prognosis of dermatofibrosarcoma protuberans in children is excellent as long as early diagnosis is followed by complete excision with Mohs surgery as a golden standard. (J Dermatol Case Rep. 2013; 7(4): 121-124)

\section{Introduction}

Dermatofibrosarcoma protuberans (DFSP) is a rare lowgrade malignancy expressing CD34. ${ }^{1}$ Its annual incidence per million inhabitants is 4.2 in the USA and 3 in France. ${ }^{2,3}$ The 5 -year survival rate for all patients is $99.2 \%{ }^{2}$ DFSP is characterized by the presence of translocation $t(17 ; 22)(q 22 ; q 13)$ that leads to a specific fusion of the platelet-derived growth factor beta (PDGFbeta) with the collagen type 1alpha1 (COL1alpha1) gene. This translocation can be detected by multiplex reverse transcriptase-polymerase chain reaction (RT-PCR) or fluorescence in situ hybridization (FISH) techniques. In routine diagnostics, histopathology and immunohistology are the hallmarks. But there are difficult cases where molecular biology techniques support confirmation of diagnosis. ${ }^{4,5}$ Other CD34-positive neoplasias include epitheloid sarcoma, spindle cell lipoma, CD34-positive cellular digital fibromas, and solitary fibrous tumors. ${ }^{6,7}$ It has been speculated that DFSP derives from a subtype of nestin-immunoreactive mesenchymal stem cell that is different from the nestin- and SOX2-positive cell population of the perifollicular mesenchyme. ${ }^{8}$ The tumor is very rare among patients younger than 18 years of life. Congential variants of DFSP have been described occasionally. ${ }^{9}$

Here we report a pediatric patient with DSFP representing as medaillon-like thoracic plaque and discuss treatment options.

\section{Case report}

A 10-year-old female patient was referred to out department for diagnostics of a rapid growing nodule of the thorax. The medical history of the girl and her family was unremarkable. The lesion was observed for a couple of months. We observed a firm slightly reddish plaque of $1.2 \mathrm{~cm}$ diameter with a slightly atrophic epidermal cover in the left subclavicular region (Fig. 1). The lesion was moveable to the underlying tissue but not the epidermis. It was painless. A skin biopsy was taken for diagnostics. The tumor was composed of relatively uniformous large spindle cells organized in a storiform pattern. Except for a subepidermal Grenz zone tumor cells were infiltrating the whole dermis and the upper subcutaneous adipose tissue.

Tumor cells were reactive with CD34 but negative for S100 (Fig. 2). Frequently mitoses were seen. Ki67 stained about $1 \%$ of tumor cells.

The diagnosis of DFSP was made.

Complete surgical excision with complete micrographical control of excision margins was performed (delayed Mohs surgery). For primary excision a margin of $2 \mathrm{~cm}$ was chosen based on recommendations of the German Society of Dermatology. ${ }^{1}$ The subcutaneous tissue was completely removed down to the fascia of intercostal muscles (Fig. 3). The defect was closed and healing was unremarkable. 


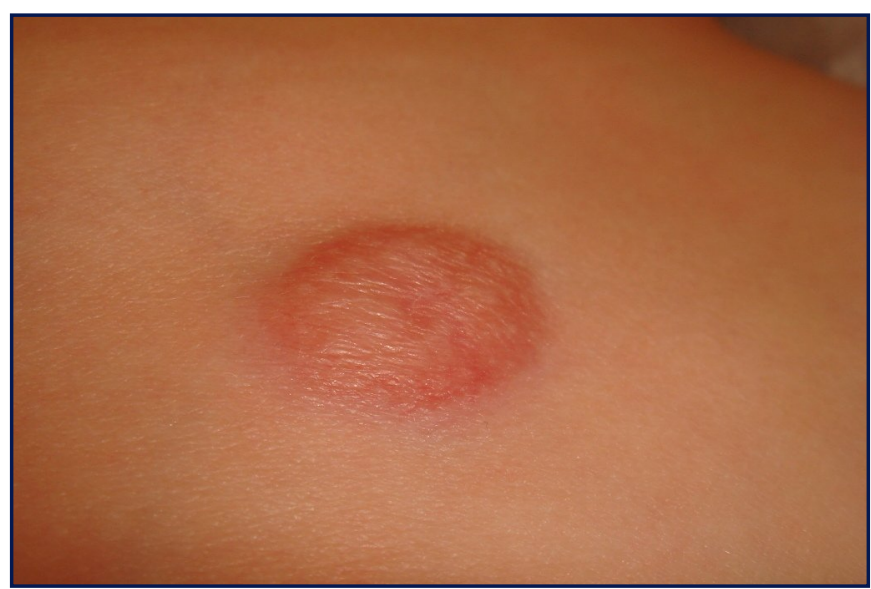

Figure 1

Clinical presentation of dermatofibrosarcoma protuberans as a painless thoracic plaque.

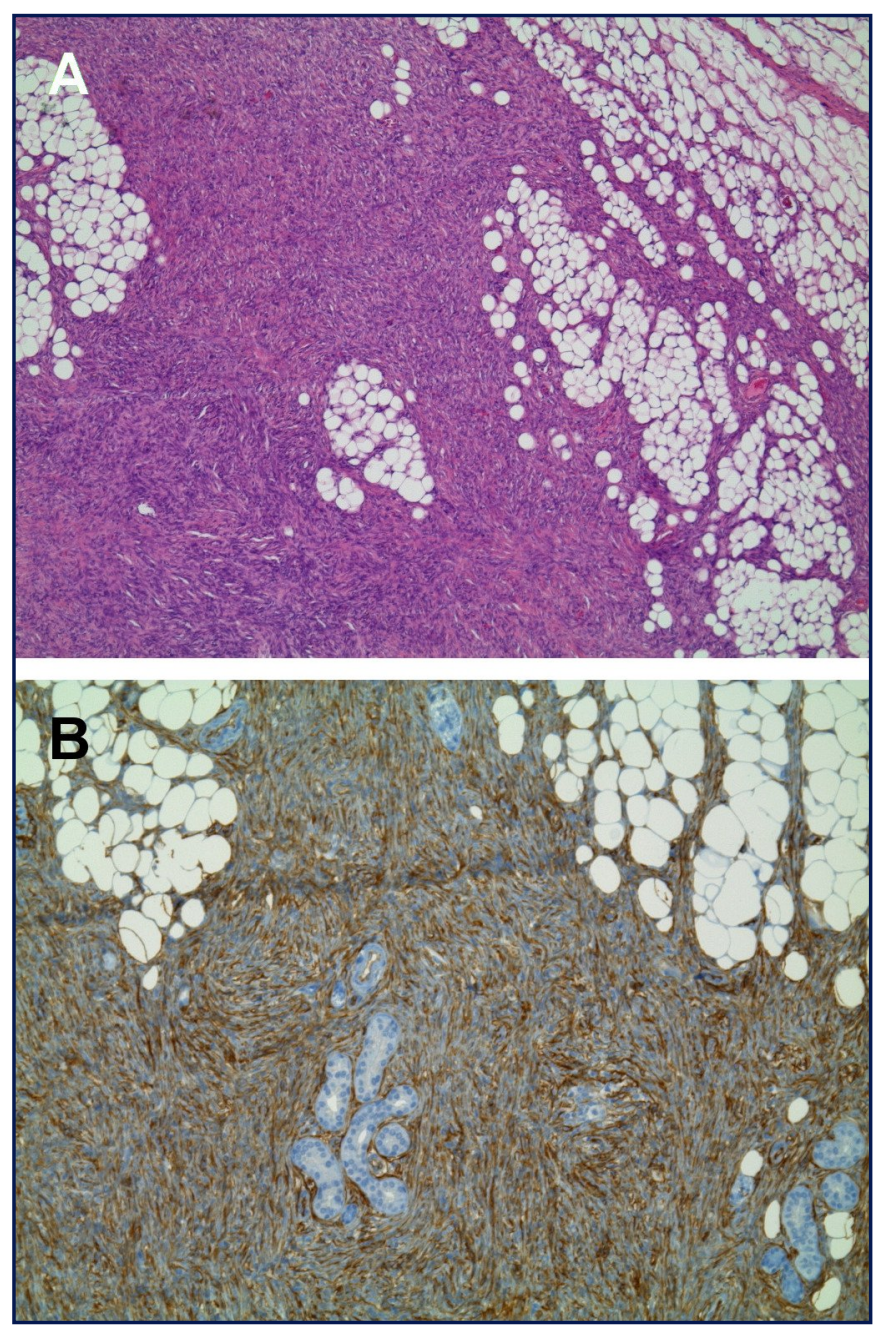

Figure 2

(A) Storiform pattern of tumor cells with a Grenz zone to the epidermis but deep infiltration of sucutaneous adipose tissue (hematoxylin-eosin, $x$ 4). (B) CD34 positivity of tumor cells (immunoperoxidase technique, $x 4$ ).

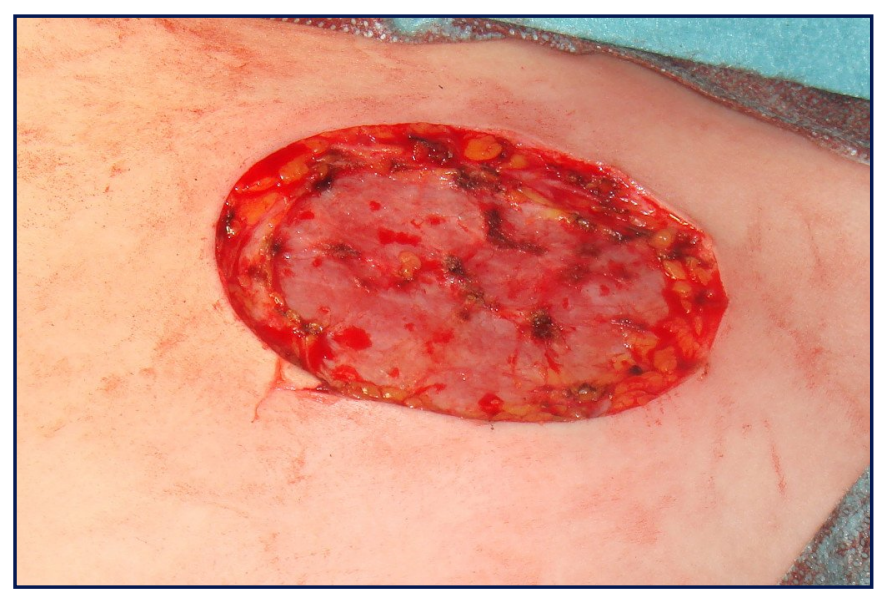

Figure 3

Operation situs with $2 \mathrm{~cm}$ safety margins and excision in the depth along the intercostal muscle fascia.

Laboratory investigations, diagnostic ultrasound of lymph nodes and abdomen did not show any abnormalities. A regular follow-up was recommended for the next 5 years. During the first year no relapse occurred.

\section{Discussion}

DFSP is a rare malignancy in childhood and adolescence. In a 25-year analysis of Taiwanese cancer registry data only 12 patients could be identified. ${ }^{10}$ A collection of 15 cases was reported during three decades from Kansas City, MO. ${ }^{11}$

Lesions can occur on any part of the body. They may appear as nodules, plaques or papules. The tumor is characterized by local infiltrative growth with high recurrence rates. This has direct implications for surgical treatment, which is the gold standard for DFSP. ${ }^{1,12}$

There is no doubt about that inadequate primary treatment of DFSP results in high recurrence rates and larger excisions. ${ }^{13}$ Controversy exists regarding margin width and excision techniques, with some advocating Mohs micrographic surgery (MMS) and others wide excision (WE). In case of WE without micrographic control of excision margins resection margins of at least $3 \mathrm{~cm}$ are recommended to reduce recurrence rate from $13.6 \%-47 \%$ to $5.7 \%-7 \%$. 3,14

Using a standardized surgical approach including meticulous pathologic evaluation of margins, a very low recurrence rate $(1 \%)$ was achieved with relatively narrow margins (median $2 \mathrm{~cm}$ ), allowing primary closure in $69 \%$ of patients. ${ }^{15}$ This approach spares the additional morbidity associated with wider resection margins.

In a retrospective study comparing the outcome after MMS with WE $13.2 \%$ of WE patients (follow-up $=4.8$ years) had recurrences during a follow-up period of 4.8 years as opposed to none MMS patients (follow-up = 5.4 years). Pooling of these data with those from the literature yielded $6 / 463$ recurrences for MMS (1.3\%) and 288/1394 recurrences for WE $(20.7 \%)$. The relative risk of recurrence for WE vs. MMS patients was 15.9 (95\% Cl 7.2-35.5). ${ }^{16}$ Five- and 10-year survival rates of $100 \%$ have been reported for MMS. ${ }^{10,17}$ 
Chemotherapy usually has a palliative character. A case report with a successful use of vinblastine and methotrexate has been published. ${ }^{18}$ That is the first report of a paediatric DFSP responding to chemotherapy. More hope was put on targeted therapies. Imatinib metylase competes with adenosine triphosphate molecule, blocking tyrosine kinase receptor ability for autophosphorylation, which in return results in inhibition of the aberrant signal transduction pathway and partial restoration of proper intracellular signaling. In clinical practise, however, imatinib produced mixed results. $^{20-22}$ Its current potential is the non-resectable DFSP. In some cases such tumors become treatable surgically after size reduction. ${ }^{23}$

In conclusion, surgical excision with clear margins is critical for cure. Micrographic control of excision margins improves outcome and reduces recurrence rates while limiting the need of closure by flaps or grafts. ${ }^{11,24-26}$ We treated our patient with micrographic controlled surgery (delayed $M M S$ ). A regular follow-up is necessary to control the outcome and minimize delay for re-treatment when needed.

DSFP is rare in patients younger than 18 years of age. But early histological confirmation of diagnosis will improve outcome and avoid larger excisions.

\section{References}

1. Ugurel S, Kortmann RD, Mohr P, Mentzel T, Garbe C, Breuninger $\mathrm{H}$. Short German guidelines: dermatofibrosarcoma protuberans. J Dtsch Dermatol Ges. 2008; 6 (Suppl 1): S1718. PMID: 18801137.

2. Criscione VD, Weinstock MA. Descriptive epidemiology of dermatofibrosarcoma protuberans in the United States, 1973 to 2002. J Am Acad Dermatol. 2007; 56: 968-973. PMID: 17141362.

3. Monnier D, Vidal C, Martin L, Danzon A, Pelletier F, Puzenat E, Algros MP, Blanc D, Laurent R, Humbert PH, Aubin F. Dermatofibrosarcoma protuberans: a population-based cancer registry descriptive study of 66 consecutive cases diagnosed between 1982 and 2002. J Eur Acad Dermatol Venereol. 2006; 20: 1237-1242. PMID: 17062038.

4. Patel KU, Szabo SS, Hernandez VS, Prieto VG, Abruzzo LV, Lazar AJ, López-Terrada D. Dermatofibrosarcoma protuberans COL1A1-PDGFB fusion is identified in virtually all dermatofibrosarcoma protuberans cases when investigated by newly developed multiplex reverse transcription polymerase chain reaction and fluorescence in situ hybridization assays. Hum Pathol. 2008; 39: 184-193. PMID: 17950782.

5. Salgado R, Llombart B, M Pujol R, Fernández-Serra A, Sanmar tín O, Toll A, Rubio L, Segura S, Barranco C, Serra-Guillén C, Yébenes $M$, Salido $M$, Traves V, Monteagudo C, Sáez E, Hernández $T$, de Álava E, Llombart-Bosch A, Solé F, Guillén C, Espinet B, López-Guerrero JA. Molecular diagnosis of dermatofibrosarcoma protuberans: a comparison between reverse transcriptase-polymerase chain reaction and fluorescence in situ hybridization methodologies. Genes Chromosomes Cancer. 2011; 50: 510-517. PMID: 21484928.
6. Tardío JC. CD34-reactive tumors of the skin. An updated review of an ever-growing list of lesions. J Cutan Pathol. 2009; 36: 89-102. PMID: 19125742.

7. Wood L, Fountaine TJ, Rosamilia L, Helm KF, Clarke LE. Cutaneous CD34+ spindle cell neoplasms: Histopathologic features distinguish spindle cell lipoma, solitary fibrous tumor, and dermatofibrosarcoma protuberans. Am J Dermatopathol. 2010; 32: 764-768. PMID: 20559119.

8. Sellheyer K, Nelson P, Patel RM. Expression of embryonic stem cell markers SOX2 and nestin in dermatofibrosarcoma protuberans and dermatofibroma. J Cutan Pathol. 2011; 38: 415-419. PMID: 21251041.

9. Maire G, Fraitag S, Galmiche L, Keslair F, Ebran N, TerrierLacombe MJ, de Prost Y, Pedeutour F. A clinical, histologic, and molecular study of 9 cases of congenital dermatofibrosarcoma protuberans. Arch Dermatol. 2007; 143: 203-210. PMID: 17310000.

10. Chien CR, Chang YL, Lin DT, Yang RS. Excellent survival of pediatric dermatofibrosarcoma protuberans in Taiwanese. Pediatr Surg Int. 2007; 23: 211-214. PMID: 17109179.

11. Iqbal CW, St Peter S, Ishitani MB. Pediatric dermatofibrosarcoma protuberans: multi-institutional outcomes. J Surg Res. 2011; 170: 69-72. PMID: 21429521.

12. Zaraa I, Ben abdallah $M$, Driss $M$, Trojjet $S$, Ben Sassi M, El Euch D, Mokni M, Rahal K, Ben Romdhane K, Ben Osman A. [Dermatofibrosarcoma protuberans in children]. Arch Pediatr. 2011; 18: 23-27. PMID: 20952167.

13. Khatri VP, Galante JM, Bold RJ, Schneider PD, Ramsamooj R, Goodnight JE Jr. Dermatofibrosarcoma protuberans: reappraisal of wide local excision and impact of inadequate initial treatment. Ann Surg Oncol. 2003; 10: 1118-1122. PMID: 14597453.

14. Cai H, Wang Y, Wu J, Shi Y. Dermatofibrosarcoma protuberans: Clinical diagnoses and treatment results of 260 cases in China. J Surg Oncol. 2012; 105: 142-148. PMID: 21815146.

15. Farma JM, Ammori JB, Zager JS, Marzban SS, Bui MM, Bichakjian CK, Johnson TM, Lowe L, Sabel MS, Wong SL, Douglas Letson G, Messina JL, Cimmino VM, Sondak VK. Dermatofibrosarcoma protuberans: how wide should we resect? Ann Surg Oncol. 2010; 17: 2112-2118. PMID: 20354798.

16. Paradisi A, Abeni D, Rusciani A, Cigna E, Wolter M, Scuderi N, Rusciani L, Kaufmann R, Podda M. Dermatofibrosarcoma protuberans: wide local excision vs. Mohs micrographic surgery. Cancer Treat Rev. 2008; 34: 728-736. PMID: 18684568.

17. Snow SN, Gordon EM, Larson PO, Bagheri MM, Bentz ML, Sable DB. Dermatofibrosarcoma protuberans: a report on 29 patients treated by Mohs micrographic surgery with long-term follow-up and review of the literature. Cancer. 2004; 101: 28-38. PMID: 15221986.

18. Ng A, Nishikawa H, Lander A, Grundy R. Chemosensitivity in pediatric dermatofibrosarcoma protuberans. J Pediatr Hematol Oncol. 2005; 27: 100-102. PMID: 15701986.

19. Price VE, Fletcher JA, Zielenska M, Cole W, Viero S, Manson DE, Stuart M, Pappo AS. Imatinib mesylate: an attractive alternative in young children with large, surgically challenging dermatofibrosarcoma protuberans. Pediatr Blood Cancer. 2005; 44: 511-515. PMID: 15503291. 
20. Gooskens SL, Oranje AP, van Adrichem LN, de Waard-van der Spek FB, den Hollander JC, van de Ven CP, van den Heuvel-Eibrink MM. Imatinib mesylate for children with dermatofibrosarcoma protuberans (DFSP). Pediatr Blood Cancer. 2010; 55: 369-373. PMID: 20582941.

21. Sugiura H, Fujiwara $Y$, Ando M, Kawai A, Ogose A, Ozaki T, Yokoyama R, Hiruma T, Ishii T, Morioka H, Mugishima H. Multicenter phase II trial assessing effectiveness of imatinib mesylate on relapsed or refractory KIT-positive or PDGFRpositive sarcoma. J Orthop Sci. 2010; 15: 654-660. PMID: 20953927.

22. Kim GK. Status report on the management of dermatofibrosarcoma protuberans: is there a viable role for the use of imatinib mesylate? In which cases may it be therapeutically helpful and in which cases not? J Clin Aesthet Dermatol. 2011; 4: 17-26. PMID: 21464883.
23. Hancox JG, Kelley B, Greenway HT Jr. Treatment of dermatofibroma sarcoma protuberans using modified Mohs micrographic surgery: no recurrences and smaller defects. Dermatol Surg. 2008; 34: 780-784. PMID: 18318720.

24. Reddy C, Hayward P, Thompson P, Kan A. Dermatofibrosarcoma protuberans in children. J Plast Reconstr Aesthet Surg. 2009; 62: 819-823. PMID: 18096453.

25. Roh MR, Bae B, Chung KY. Mohs' micrographic surgery for dermatofibrosarcoma protuberans. Clin Exp Dermatol. 2010; 35: 849-852. PMID: 20456396.

26. Bakry O, Attia A. Atrophic dermatofibrosarcoma protuberans. J Dermatol Case Rep. 2012; 6: 14-17. PMID: 22514584. 